
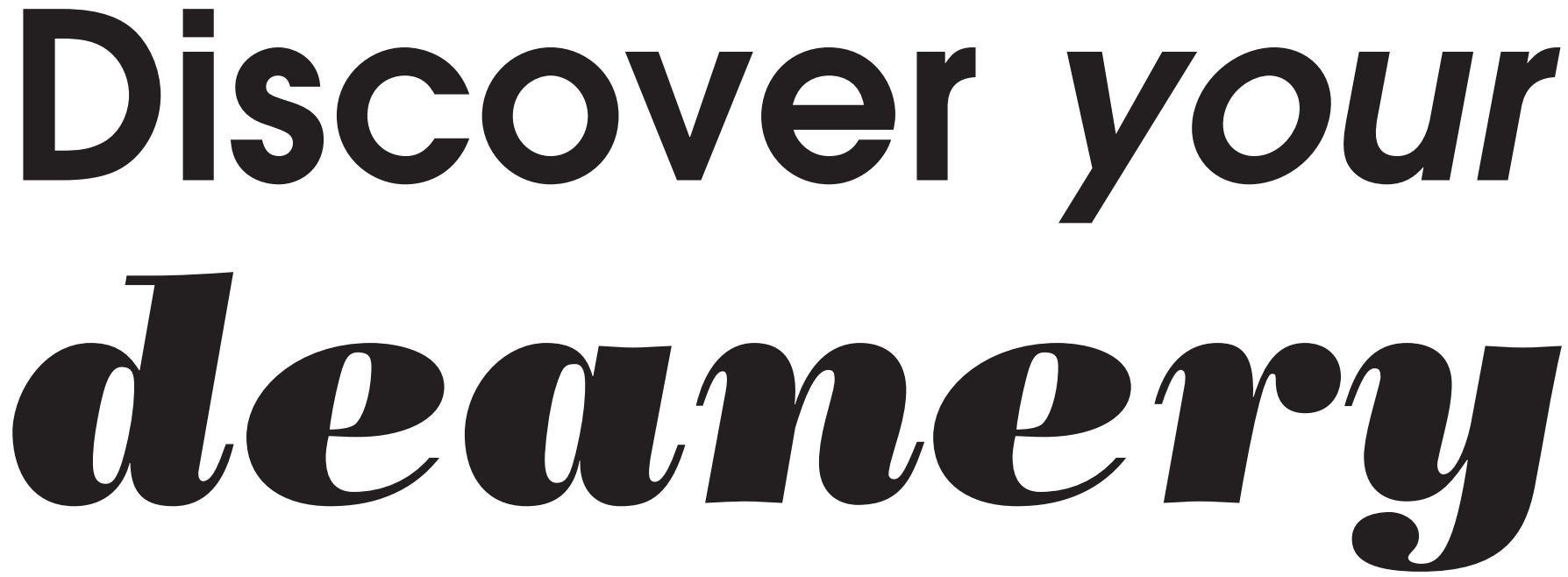

Just who is your local deanery? What do they do? How can you contact them? Kathryn Marshall, DCP Tutor for Kent, Surrey \& Sussex Deanery, offers some advice.

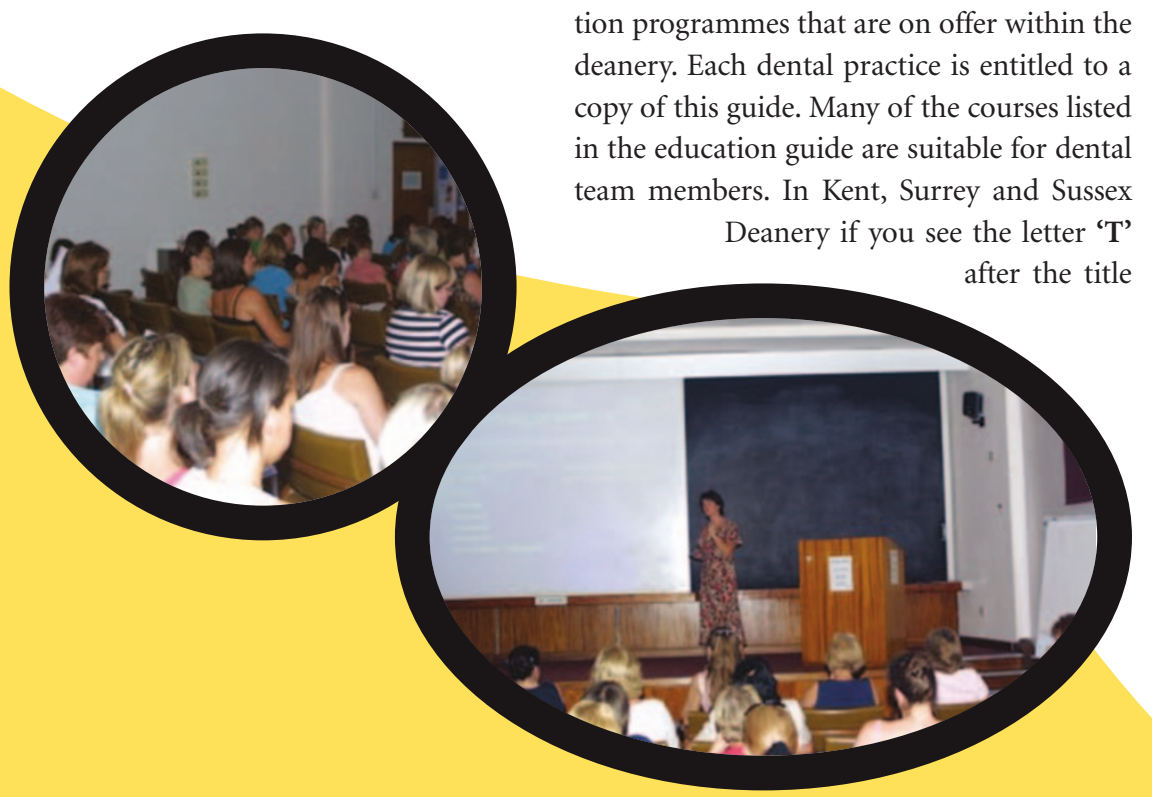

14 winter 06 vital

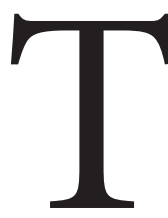

he deanery coordinates the delivery and funding of postgraduate medical and dental education in your particu-

lar region. Their mission is to deliver high quality programmes and training events for the whole dental team. Each one of you will have a local deanery.

You may be aware that some of the dentists that you work with attend courses at their local postgraduate centre. What you may not realise is that you are also able to attend some of these courses.

Every year your deanery publishes either a hard copy or web-based guide of all education programmes that are on offer within the deanery. Each dental practice is entitled to a copy of this guide. Many of the courses listed in the education guide are suitable for dental team members. In Kent, Surrey and Sussex Deanery if you see the letter ' $T$ ' after the title

2009 the GDC will introduce mandatory CPD for all DCPs so it is a good idea to form a relationship with your local established training provider at an early date. Contact the postgraduate centre that is most convenient for you to attend and ask for a list of courses they have available specifically for the dental team.

Most deaneries will have a DCP tutor who is assigned to look after the educational needs of all DCPs. Their role is to design, facilitate, provide and support training that will meet the needs of the DCPs working within their local dental work environment. Look at the introduction at the start of your 


\section{focus on deaneries:}

deanery booklet and make a note of this person's details. Make contact with them. Ask what provisions they have for DCP training. Ask to be placed on their database so that you will be kept informed of what is happening in education in your area. If you have a specific training need you can discuss it with them. Most courses will be subsidised.

\section{'Contact the} postgraduate centre that is

\section{most convenient} for you to attend and ask for a list of courses they have available specifically for the dental team.'

At Kent, Surrey and Sussex Deanery, we have a new programme for registered dental nurses leading to the National Examining Board's Certificate for Dental Nurses in Dental Radiology. The course is designed to prepare dental nurses for the theoretical aspect of the certificate. In addition to this we are offering full support from a Dental Nurse Tutor who already holds the Certificate in Dental Radiology. She will help steer nurses and their supervising dentist in their own practice environment through the 'Record of Experience'. This provides the portfolio of evidence necessary for completion of the certificate. The purpose of the 'Record of Experience' is for dental nurses to gain practical experience and competency in dental radiography techniques.

In early 2007 we will be offering a course leading to the NEBDN Certificate in Oral Healthcare, of special interest to any dental nurse who has a real interest in a prevention role in his or her practice.

Other areas that the Kent, Surrey and Sussex Deanery are working on are issues around GDC registration. Although exciting, registration brings forth a number of issues on which dental nurses may require clarification, namely employment protection, indemnity insurance and the routes available to registration.

The Deanery appreciates that many may not know where to start to find out about these issues and has arranged three special evenings to address them. Speakers come from the GDC, the Dental Defence Union, Unison, and the Deanery to give facts and information on what registration really means for you as a dental nurse. The Deanery is also running a series of road shows for dental hygienists and therapists and programmes especially for dental practice receptionists and managers.

If you have any thoughts, ideas or comments on education and training issues for DCPs you should contact your local deanery and discuss them with the DCP Tutor.

For more information on Kent, Surrey and Sussex Deanery telephone 0207415 3400, visit www.kssdeanery.ac.uk or email the DCP Tutor at kathrynm@btconnect.com.

What's happening in your PCT?

Is your surgery involved with any special events or schemes, or been rewarded for innovation?

If you are interested in being featured in a Focus on, contact Arveen Bajaj on a.bajaj@nature.com or telephone 02078433679.

\section{A RECORD FINISH}

You will need to make a record of what training and education you have received. Keep all certificates for any course you may attend or learning that took place in your work environment. Start a portfolio of evidence both as a reminder of just how much new knowledge you have gained, and also in readiness for when CPD will be compulsory. The BDA has a planner available so you can keep all your paperwork together either in folder form or CD-ROM on your computer.

When the 'Dental Courses Guide' from your local deanery arrives in the practice post, grab it first! This will tell you what education is available in your area for the next 12 months. Check to see if your guide is 'flagged up' for courses that are suitable for DCPs. If it isn't, ask for this in the future.

It may be another three years before the GDC introduce verifiable CPD. However, dental nurses in particular are used to thinking ahead and anticipating what the dentist needs well in advance of them asking for it. Adapting to the ethos of 'lifelong learning' will be second nature for most of us 